\title{
A two dimensional, reaction-diffusion model of compost piles
}
T. Luangwilai ${ }^{1}$
H. S. Sidhu ${ }^{2}$
M. I. Nelson ${ }^{3}$

(Received 6 January 2012; revised 17 April 2012)

\begin{abstract}
We consider the self heating process in a two dimensional spatially dependent model of a compost pile which incorporates terms that account for self heating due to both biological and oxidation mechanisms. As moisture is a crucial factor in both the degradation process and spontaneous ignition within a compost pile, this model consists of four mass-balance equations, namely, energy, oxygen, vapour and liquid water concentrations. Analyses are undertaken for different initial water contents within the compost pile. We show that when the water content is too low, the reaction is almost negligible; whereas when it is too high, the reaction commences only when the water content evaporates and the water ratio drops to within an appropriate range. However, for an intermediate water content range, the biological reaction is at its optimum and there is a possibility of spontaneous ignition within the compost pile.
\end{abstract}

http://journal.austms.org.au/ojs/index.php/ANZIAMJ/article/view/5083 gives this article, (c) Austral. Mathematical Soc. 2012. Published April 25, 2012. IsSN 1446-8735. (Print two pages per sheet of paper.) Copies of this article must not be made otherwise available on the internet; instead link directly to this URL for this article. 


\section{Contents}

1 Introduction

C35

2 Governing equations

C36

3 Numerical solutions

C40

4 Results

4.1 Low initial moisture content case $(\sigma(0)=0.1) \ldots \ldots$ C41

4.2 Intermediate initial moisture content case $(\sigma(0)=0.5) \quad$.

$\mathrm{C} 43$

4.3 High initial moisture content case $(\sigma(0)=0.8) \ldots \ldots$

5 Conclusions

C46

6 Nomenclature

C47

References

C49

\section{Introduction}

Industrial compost piles contain large volumes of bulk organic materials and, typically, two sources of heat generation: the oxidation of cellulosic materials; and biological activity [17]. The first of these represents chemical heat generation and may be modelled by a single Arrehenius reaction [2]. Biological processes that lead to heat generation include the growth and respiration of microorganisms, such as aerobic mould-fungi and bacteria. This biological heating, which occurs at lower temperatures than oxidation, may increase the temperature to a sufficiently high level to 'kick start' the oxidation reaction. Biological heating is known to be important in large scale composting operations [17] and in the storage of industrial waste fuels, such as municipal solid waste and landfill [9]. Indeed, in composting, self heating due to biological activity is desirable [3]. 
Biological activity is known to work efficiently in the elevated temperature range of $50^{\circ} \mathrm{C}$ to $90^{\circ} \mathrm{C}$ which can occur within a few months or even a few days [8]. It has been recognised for almost thirty years that "... biological heating may be an indispensable prelude to self ignition" [2]. However, mathematical modelling for investigating the spontaneous combustion of compost piles due to biological self heating is very limited.

Moisture is also one of the key factors for sustaining the biological reaction within a compost pile, with its optimal content for biological activity believed to be between approximately 40 and 60 percent of the water-to-compost weight ratio $[7,12,17]$. This is because, when there is too little moisture, the metabolism of microorganisms cannot be sustained. On the other hand, when there is too much moisture, the metabolism of micro-organisms is inefficient. Furthermore, any rise in temperature is accompanied by evaporation.

Sidhu et al. [20] developed and investigated a spatially distributed model for both biological and chemical self heating, with oxygen consumption but without moisture content. Moraga et al. [15] showed explicitly from their experimental data of a sewage sludge pile that the model by Sidhu et al. [20] provides reasonable predictions of temperature increases within the pile. Luangwilai et al. [13] extended the model of Sidhu et al. [20] by including the effects of moisture content on the behaviour of a compost pile in a one dimensional model. The current investigation extends the study further to a two dimensional model. We investigate the behaviour of temperature profiles within the pile for different initial moisture-to-compost weight ratios.

\section{Governing equations}

We consider a two dimensional model with the geometry of an infinite trapezoidal slab (that is, an infinitely long slab) with thickness (width) L, and height $\mathrm{H}$ (Figure 1). This trapezoidal configuration has been widely used in both coal and compost models $[1,15]$ and is one of the common configu- 


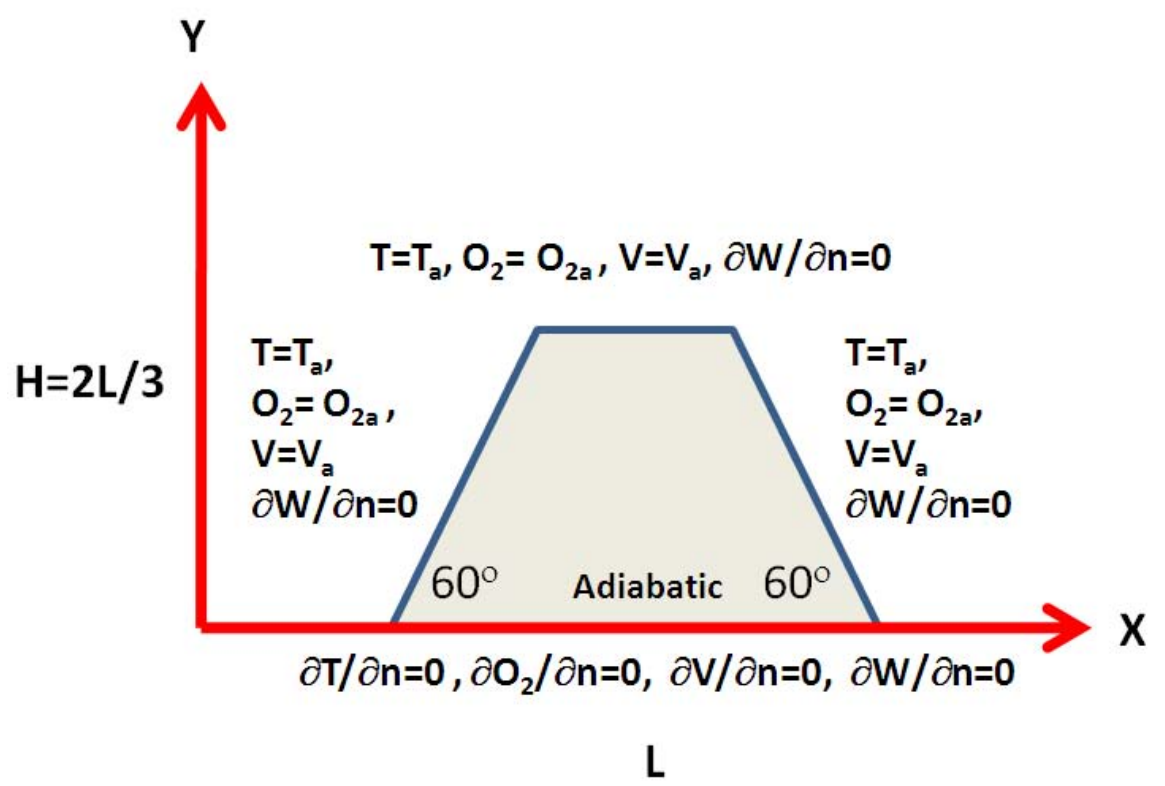

Figure 1: Schematic diagram showing cross-sectional geometry of infinitely long compost pile and corresponding boundary conditions.

rations for industrial composting. An industrial compost pile size can vary between $6 \mathrm{~m}$ and $30 \mathrm{~m}$ in both height and width, and a few hundred metres in length [7, 17]. Following the work of Krajčiová et al. [11], the angle at the base of the slab is set to 60 degrees, as in the coal model.

In this investigation, depletions of cellulosic materials and biomass, and interphase (solid particles and gas) temperature gradients are ignored as we believe their effects are negligible for large compost piles as well as for the range of temperatures considered in this study. Therefore, a single temperature is used to describe local behaviour, that is, the compost pile is assumed to be at a local thermal equilibrium which is a common assumption made for porous media and packed particle beds [16].

To investigate the effects of moisture within compost piles, we extend the 
basic model of Sidhu et al. [20]; that is, Equations (1) and (2) that describe the temperature and oxygen distributions within the pile, respectively, to the equations describing the liquid and vapour concentrations (Equations (3) and (4), respectively). Hence, the governing equations describing the temperature $\mathrm{T}$, oxygen concentration $\mathrm{O}_{2}$, vapour concentration $\mathrm{V}$, and liquid water concentration $W$, in the $0 \leqslant x \leqslant L$ and $0 \leqslant y \leqslant H$ domains are as follows.

\section{Governing equations}

$$
\begin{aligned}
& (\rho C)_{\text {eff }} \frac{\partial T}{\partial t}=k_{\text {eff }} \nabla^{2} T+\mu_{1}(W) Q_{c} \rho_{c} A_{3} O_{2} M_{O_{2}}(1-\epsilon) e^{-E_{3} / R T} \\
& +\mu_{2}(W) Q_{b} \rho_{b}(1-\epsilon) \frac{A_{1} e^{-E_{1} / R T}}{1+A_{2} e^{-E_{2} / R T}}+L_{v}\left(\epsilon Z_{c} V-(1-\epsilon) Z_{e} W e^{-L_{v} / R T}\right) \\
& \epsilon \frac{\partial O_{2}}{\partial t}=D_{O_{2} e f f} \nabla^{2} O_{2}-\mu_{1}(W) \rho_{c} A_{3} O_{2}(1-\epsilon) e^{-E_{3} / R T} \\
& \epsilon \frac{\partial V}{\partial t}=-\epsilon Z_{c} V+(1-\epsilon) Z_{e} W e^{-L_{v} / R T}+D_{V} \nabla^{2} V \\
& (1-\epsilon) \frac{\partial W}{\partial t}=\epsilon Z_{c} V-(1-\epsilon) Z_{e} W e^{-L_{v} / R T}
\end{aligned}
$$

\section{Algebraic relationships}

$$
\begin{aligned}
& k_{\text {eff }}=\epsilon k_{\text {air }}+(1-\epsilon)\left(\sigma k_{w}+(1-\sigma) k_{c}\right), \\
& (\rho C)_{e f f}=\epsilon \rho_{\text {air }} C_{\text {air }}+(1-\epsilon)\left(W_{w} C_{w}+\rho_{\text {compost }} C_{c}\right) \text {, } \\
& \mathrm{D}_{\mathrm{O}_{2} \text { eff }}=\mathrm{D}_{\mathrm{V}}=\epsilon \mathrm{D}_{\mathrm{O}_{2} \text { air }} \text {, } \\
& \mu_{1}(W)= \begin{cases}1-\left(W / W_{c}\right)^{b}, & W<W_{c}, \\
0, & W \geqslant W_{c},\end{cases} \\
& \mu_{2}(W)= \begin{cases}\frac{\sigma-\sigma_{a}}{\sigma_{\mathfrak{m}}-\sigma_{a}}, & \sigma_{\mathfrak{a}} \leqslant \sigma \leqslant \sigma_{\mathfrak{m}} \\
\frac{\sigma_{\mathfrak{b}}-\sigma}{\sigma_{\mathfrak{b}}-\sigma_{\mathfrak{m}}}, & \sigma_{\mathrm{m}} \leqslant \sigma \leqslant \sigma_{\mathfrak{b}}, \\
0, & \text { otherwise. }\end{cases}
\end{aligned}
$$


The terms in Equations (1) to (9) are defined in the nomenclature (Section 6). The physical parameters are considered to be independent of the temperature and oxygen vapour and liquid water concentrations.

The heat generation and oxygen consumption caused by the oxidation of cellulosic materials are represented by the second terms on the right-hand sides of Equations (1) and (2), respectively. The heat generated by biological activity is represented by the third term on the right-hand side of equation (1); such an approach for modelling biological activity has been used in a number of models for solid state fermentation processes [10].

Equations (3) and (4) represent the evaporation and condensation processes within the compost pile. An energy change from these reactions is represented by the fourth term in Equation (1). These equations are based on the works of Gray et al. [6], Sexton et al. [18] and Sisson et al. [19]. These authors developed models for the self heating process within a bagasse pile that include the effects of variations in state between the vapour and liquid water within a pile and the resultant energy changes. The models were validated by experimental data from a bagasse stockpile.

The algebraic expressions (5) and (6) define the effective thermal conductivity and effective thermal capacity of the compost pile, respectively, in terms of the corresponding properties of air, the compost materials and the moisture content. Equation (7) defines the effective diffusion coefficients for oxygen and vapour.

The effects of moisture on the oxidation and biological reactions are defined in expressions (8) and (9), respectively. To describe these effects on the oxidation reaction, we adopt the assumption of Chen [4] which is that increasing the liquid water content within the pile decreases the oxidation reactions due to the reaction site being covered by water. Beyond the critical value of $W_{c}$, the oxidation reaction ceases since the liquid water fully covers all the reaction sites.

To model the effects of moisture on the biological reaction, we follow the 
approach of Kuwahara et al. [12]. The biological reaction normally activates when the water-to-compost weight ratio reaches a threshold value of $\sigma_{a}$. Similarly, it deactivates and ceases if the moisture content ratio is greater than the upper threshold of $\sigma_{\mathrm{b}}$. Between these two ratios, the biological reaction is optimum at the value $\sigma_{\mathrm{m}}$.

In this analysis, we assume simple boundary conditions for the system. We apply an insulated boundary at the base of the compost pile $\left(\frac{\partial \mathrm{T}}{\partial \mathrm{n}}=0, \frac{\partial \mathrm{O}_{2}}{\partial \mathrm{n}}=0\right.$, $\frac{\partial V}{\partial n}=0$ and $\left.\frac{\partial W}{\partial n}=0\right)$. For the other boundaries, the values of the temperature, oxygen and water vapour are assumed to equal the ambient conditions $\left(T=T_{a}\right.$, $\mathrm{O}_{2}=\mathrm{O}_{2 \mathrm{a}}$ and $\mathrm{V}=\mathrm{V}_{\mathrm{a}}$ ) but, for the liquid water, which it is assumed cannot escape from the compost pile, we still apply the insulating condition $\left(\frac{\partial W}{\partial n}=0\right)$. The initial values of the temperature, oxygen and water vapour distributions within the pile are assumed to be uniform and equal to the ambient conditions. However, the initial value of the liquid water within the pile is varied and the corresponding behaviour of the compost pile is studied.

\section{$3 \quad$ Numerical solutions}

In the next section, the results from the numerical investigation of the governing equations (1) to (4) and their corresponding boundary conditions are presented. They are obtained using the software package FlexPDE ${ }^{\mathrm{TM}}$ [5], a space and time adaptive finite element package which minimises errors to a relative error tolerance of less than $0.1 \%$.

The FlexPDE ${ }^{\mathrm{TM}}$ results have been independently verified by Lungwilai and Sidhu [14] who used the method of lines. They found that the results obtained using FlexPDE ${ }^{\mathrm{TM}}$ and the method of lines are almost identical, with the maximum steady state temperature difference being less than $0.5^{\circ} \mathrm{K}$. These two methods also predict the same values for the bifurcation parameters at the limit points. The parameter values used in this investigation are based on those used by Gray et al. [6], Kuwahara et al. [12] and Sidhu et al. [20], 
and are provided in the nomenclature (Section 6).

\section{$4 \quad$ Results}

In this section, we investigate the effects of moisture within the pile. Similar to the analyses by Luangwilai et al. [13], we set the initial moisture content within the pile, that is, the value of $\sigma(0)$ (the parameter that represents the water-to-compost weight ratio), and then numerically integrate the governing PDEs and corresponding algebraic equations (1)-(9).

Sidhu et al. [20] studied models without moisture content and found that, if the compost pile is too small, its temperature remains in the low temperature region which is not ideal for the biological reaction whereas, for a larger compost pile, the temperature is able to rise to the desirable range (around 50 to $80^{\circ} \mathrm{C}$ ). However, by further increasing the compost pile size, the possibility of spontaneous combustion also increases. In this analysis, we set the width L of the compost pile to $20 \mathrm{~m}$ and its height to $2 \mathrm{~L} / 3$, a size considered to be sufficiently large to ensure that its temperature is able to increase to the high temperature range, and the effects of the moisture content on self heating can be studied.

\subsection{Low initial moisture content case $(\sigma(0)=0.1)$}

In this case, the initial water-to-compost weight ratio is set to $\sigma(0)=0.1$, that is, initially there is only 10 percent of water-to-compost weight within the pile. Thus, the pile is considered to be reasonably dry since the typical water content varies from 40 to 80 percent for organic materials depending on their types $[7,17]$. Figure 2 shows the time profiles of the maximum temperature, minimum oxygen concentration and water-to-compost weight ratio which, in this case, are almost unchanged for the whole integration time. This is because the water content is too low for microbial activity and there 


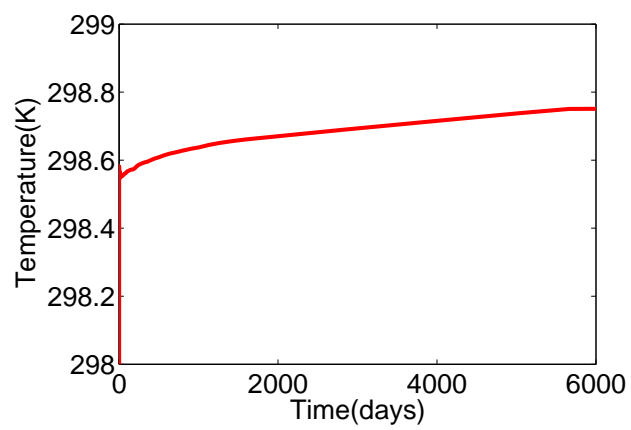

(a)

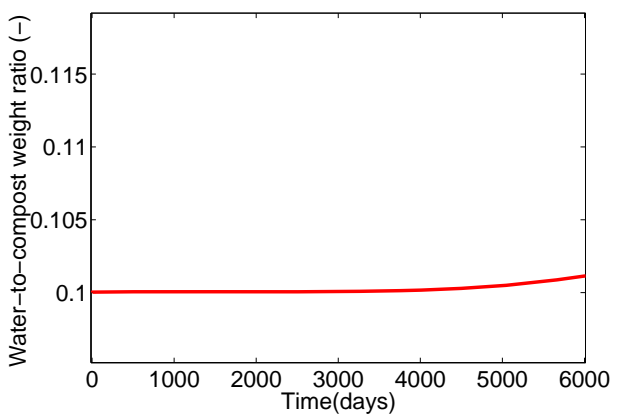

(c)

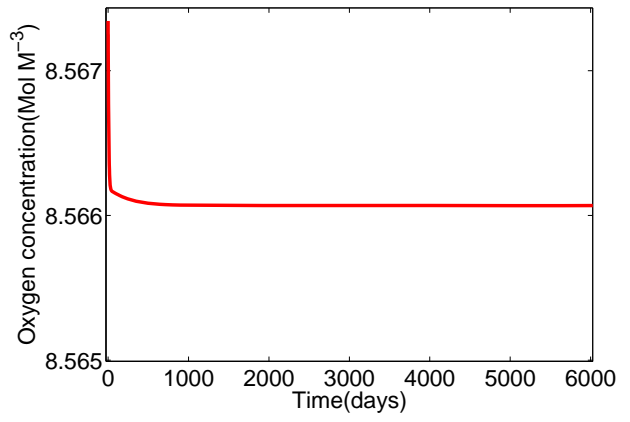

(b)

Figure 2: Time profiles within compost pile with parameter $\sigma(0)=$ 0.1: (a) maximum temperature; (b) minimum oxygen concentration; and (c) minimum liquid water-tocompost weight ratio.

is hardly any biological heating occurring within the pile. Therefore, the values of the temperature, oxygen and water-to-compost weight ratio remain almost at the ambient values for the entire time (noting that oxidation does not occur in low temperature regions).

Haug [7] suggested that composting is a dehydrating environment. When the moisture content within a compost pile is too low, it is often necessary to add water throughout the composting process to enhance the biological reaction and accelerate degradation. 


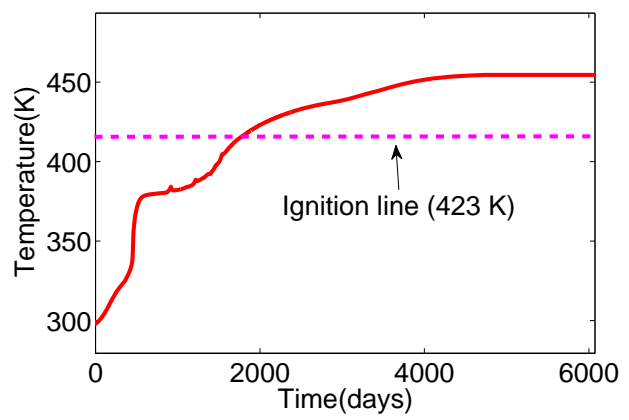

(a)

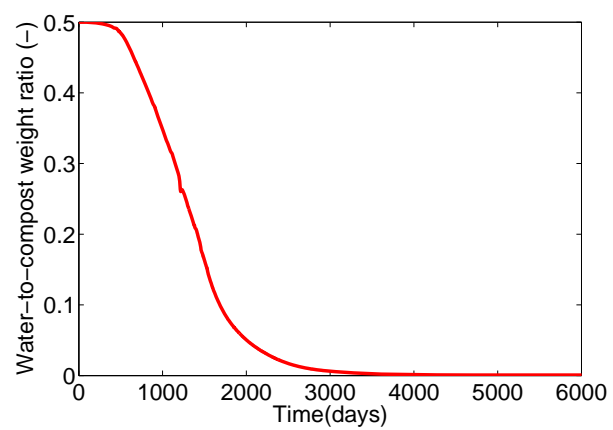

(c)

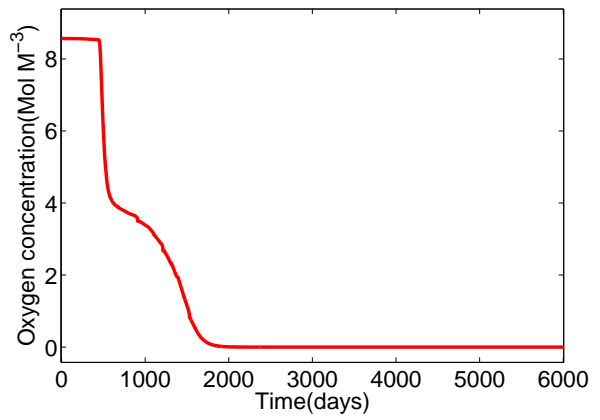

(b)

Figure 3: Time profiles within compost pile with parameter $\sigma(0)=$ 0.5: (a) maximum temperature; (b) minimum oxygen concentration; and (c) minimum liquid water-tocompost weight ratio.

\subsection{Intermediate initial moisture content case $(\sigma(0)=0.5)$}

Now, the initial water-to-compost weight ratio is increased to $\sigma(0)=0.5$ which is within the ideal range for the biological process. The temperature profile in Figure 3(a) increases and reaches the desirable temperature range of 323 to $363^{\circ} \mathrm{K}$ [17] within 280 days. At this point, the oxygen concentration starts decreasing rapidly (Figure $3(\mathrm{~b})$ ) which is an indication of the oxidation reaction being activated. The water content ratio (Figure $3(\mathrm{c})$ ) also decreases as the evaporation rate increases due to the effect of higher temperatures. 
Subsequently, the compost temperature gradually increases until it reaches the steady state temperature of around $454^{\circ} \mathrm{K}$ at approximately 4500 days. Both the oxygen concentration and water-to-compost weight ratio are reduced to almost zero at approximately 1800 and 3000 days, respectively.

At around 1980 days, the temperature within the compost pile increases beyond $423^{\circ} \mathrm{K}\left(150^{\circ} \mathrm{C}\right)$, as represented by the pink horizontal dashed line in Figure 3(a). This temperature is known to be a typical ignition temperature for compost materials [17]. The transition from an elevated temperature solution to a flaming combustion solution is 'smooth' and not characterised by a bifurcation, or 'jump'.

In this case, there is sufficient water content to sustain the biological process. The temperature increases very quickly at the beginning and, when it becomes too high, the biological activity diminishes but the oxidation reaction 'kicks in' which gradually slows down due to an insufficient supply of oxygen within the pile.

\subsection{High initial moisture content case $(\sigma(0)=0.8)$}

Figure 4 represents the results for the high initial moisture content case in which the water-to-compost weight ratio is set to $\sigma(0)=0.8$. Initially all the temperature, oxygen concentration and water-to-compost ratio profiles stay close to the ambient conditions for a very long time. However, during this period, the water-to-compost weight ratio decreases gradually due to the evaporation process. Once the water-to-compost weight ratio drops within the optimal range of the biological reaction, the heat generation process increases. This results in a rapid rise in temperature at around 15,000 days. From this point, the temperature, oxygen concentration and water ratio profiles resemble those of the previous case, that is, when the temperature reaches the elevated range of around $360^{\circ} \mathrm{K}$, its rise slows down. Then, it gradually increases until it reaches the steady state temperature of $455^{\circ} \mathrm{K}$ (23,500 days). 


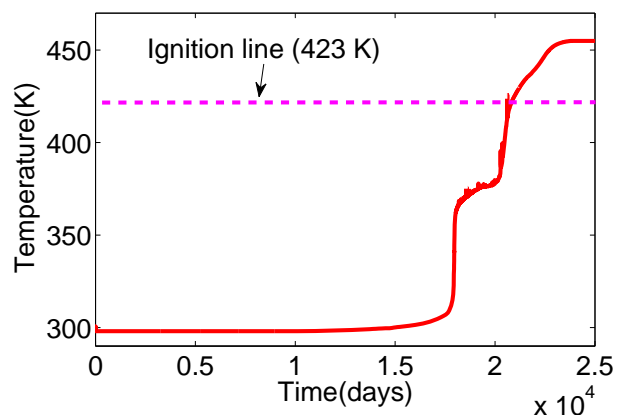

(a)

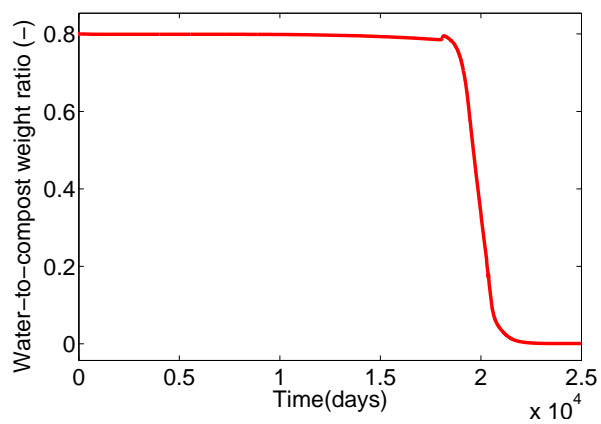

(c)

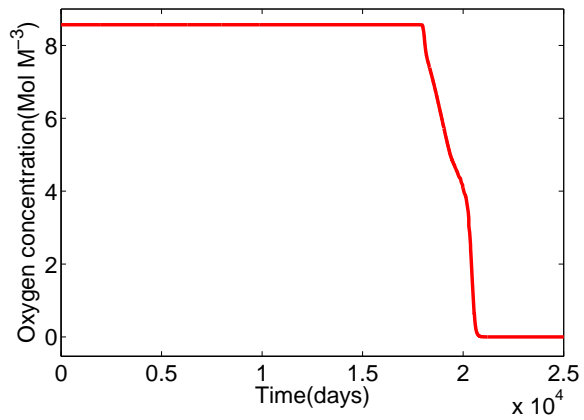

(b)

Figure 4: Time profiles within compost pile with parameter $\sigma(0)=$ 0.8: (a) maximum temperature; (b) minimum oxygen concentration; and (c) minimum liquid water-tocompost weight ratio.

In this case, initially there is too much moisture for the biological process to work efficiently. The oxidation process also ceases because water covers the entire reaction cell site. It takes a very long time for the evaporation process to decrease the moisture content to within the desirable range for biological activity. Once again, we believe that when convection is taken into considerationt the drying process will be faster.

Haug [7] stated that, in the composting of municipal and industrial biosolids, sometimes the organic materials contain a significant amount of water (70 to 80 percent). The presence of too much water results in the slowing down of 
the biological reaction and the cooling of the compost temperature to below the desirable range.

For a high water content, a higher void fraction within the pile is needed for dewatering which can be achieved by mixing materials or using different designs of a windrow compost pile [7, 17]. In some cases, an engineer may use air flow to dry the compost heap. Another problem of an outdoor compost pile is that sometimes rain increases the water content and slows the composting process.

\section{Conclusions}

We used a two dimensional, spatially dependent, model to investigate the self heating of a compost pile with different initial water-to-compost weight ratios. The results were similar to those for the one dimensional model studied by Luangwilai et al. [13].

If the moisture content is too low, there is insufficient moisture to sustain the biological reaction, resulting in low temperatures and a very slow degradation process. For an intermediate water content, the biological process works more efficiently and elevates the temperature to the desirable range for the biological reaction. Once at this elevated temperature range, the oxidation reaction commences and the water content drops quickly which has two effects: it slows the biological reaction; and increases the possibility of spontaneous ignition. On the other hand, if the compost material contains too much moisture, the biological reaction initially slows down and the excess water has to be removed. Once the water content drops to the ideal level, decomposition of the organic materials commences as the biological reaction 'kicks in'.

We plan to extend the current investigation by including terms describing the convection of air and vapour from the ambient surroundings into the compost pile. We will also investigate the effects of the boiling of water at high temperatures. We believe that, by including such factors in our model, 
we are a step closer to developing a realistic model for describing the self heating process in an industrial size compost pile.

Acknowledgements TL thanks CSIRO and ANZIAM for the Student Support Scheme which provided the funds for accommodation and travel during the EMAC 2011 conference, and also the School of PEMS, Unsw, Canberra.

\section{Nomenclature}

$A_{1}$ Pre-exponential factor for oxidation of biomass growth $\left(2 \times 10^{8} \mathrm{~m}^{3} \mathrm{~kg}^{-1} \mathrm{~s}^{-1}\right)$

$A_{2}$ Pre-exponential factor for inhibition of biomass growth $\left(6.86 \times 10^{30}\right)$

$A_{C}$ Pre-exponential factor for oxidation of cellulosic material $\left(1 \times 10^{7} \mathrm{~m}^{3} \mathrm{~kg}^{-1} \mathrm{~s}^{-1}\right)$

b Constant for moisture covering effect (1.5)

$\mathrm{C}_{\text {air }}$ Heat capacity of air $\left(1005 \mathrm{~J} \mathrm{~kg}^{-1} \mathrm{~K}^{-1}\right)$

$\mathrm{C}_{\mathrm{c}}$ Heat capacity of cellulosic material $\left(3320 \mathrm{~J} \mathrm{~kg}^{-1} \mathrm{~K}^{-1}\right)$

$\mathrm{C}_{w}$ Heat capacity of water $\left(4190 \mathrm{~J} \mathrm{~kg}^{-1} \mathrm{~K}^{-1}\right)$

$\mathrm{D}_{\text {oair }}$ Diffusion coefficient for oxygen $\left(2.5 \times 10^{-5} \mathrm{~m}^{2} \mathrm{~s}^{-1}\right)$

$\mathrm{D}_{\text {oeff }}$ Effective diffusion coefficient for oxygen $\left(7.5 \times 10^{-6} \mathrm{~m}^{2} \mathrm{~s}^{-1}\right)$

$\mathrm{D}_{v}$ Diffusion coefficient for vapour $\left(7.5 \times 10^{-6} \mathrm{~m}^{2} \mathrm{~s}^{-1}\right)$

$E_{1}$ Activation energy for biomass growth $\left(100 \times 10^{3} \mathrm{~J} \mathrm{~mol} \mathrm{biomass}^{-1}\right)$

$E_{2}$ Activation energy for inhibition of biomass growth $\left(200 \times 10^{3} \mathrm{~J} \mathrm{~mol} \mathrm{biomass}^{-1}\right)$

$E_{C}$ Activation energy for oxidation of cellulosic material $\left(110 \times 10^{3} \mathrm{~J} \mathrm{~mol}^{-1}\right)$

H, L Height and width of compost pile (m)

$k_{\text {air }}$ Effective thermal conductivity of air $\left(0.026 \mathrm{~W} \mathrm{~m}^{-1} \mathrm{~K}^{-1}\right)$ 
$k_{c}$ Effective thermal conductivity of cellulose $\left(0.3 \mathrm{~W} \mathrm{~m}^{-1} \mathrm{~K}^{-1}\right)$

$k_{\text {eff }}$ Effective thermal conductivity of bed $\left(\mathrm{W} \mathrm{m}^{-1} \mathrm{~K}^{-1}\right)$

$k_{w}$ Effective thermal conductivity of water $\left(0.58 \mathrm{~W} \mathrm{~m}^{-1} \mathrm{~K}^{-1}\right)$

$\mathrm{L}_{v}$ Latent heat of vapourisation $\left(42 \times 10^{3} \mathrm{~J} \mathrm{~mol}^{-1}\right)$

$M_{w}$ Mass of water $\left(0.018 \mathrm{~kg} \mathrm{~mol}^{-1}\right)$

$\mathrm{M}_{\mathrm{O}_{2}}$ Mass of oxygen $\left(0.032 \mathrm{~kg} \mathrm{~mol}^{-1}\right)$

$\mathrm{O}_{2}, \mathrm{O}_{2 \mathrm{a}}$ Oxygen and ambient oxygen concentrations within pile $\left(\mathrm{O}_{2 \mathrm{a}}=\right.$ $8.5675 \mathrm{~mol} \mathrm{~m}^{-3}$ )

$\mathrm{Q}_{\mathrm{b}}$ Exothermicity for oxidation of biomass per kilogram of cellulose $(6.6 \times$ $10^{6} \mathrm{~J} \mathrm{~kg}^{-1}$ )

$Q_{c}$ Exothermicity for oxidation of cellulosic material $\left(1.7 \times 10^{7} \mathrm{~J} \mathrm{~kg}^{-1}\right)$

$\mathrm{R}$ Ideal gas constant $\left(8.31441 \mathrm{~J} \mathrm{~K}^{-1} \mathrm{~mol}^{-1}\right)$

RH Relative humidity percentage (50\%)

$\mathrm{T}, \mathrm{T}_{\mathrm{a}}$ Temperature and ambient temperature $\left(\mathrm{T}_{\mathrm{a}}=298^{\circ} \mathrm{K}\right)$

$\mathrm{t}$ Time $(\mathrm{s})$

$\mathrm{V}, \mathrm{V}_{\mathrm{a}}$ Vapour and ambient vapour concentrations $\left(\mathrm{V}_{\mathrm{a}}=1.74 \times \mathrm{RH} \mathrm{mol} \mathrm{m}^{-3}\right)$

$W$ Liquid water $\left(\mathrm{mol} \mathrm{m}^{-3}\right)$

$W_{c}$ Critical liquid water effectively covering all available site $\left(300 / 0.018 \mathrm{~mol} \mathrm{~m}^{-3}\right)$

$x, y$ Spatial distance along width and height of pile $(\mathrm{m})$

$\mathrm{Z}_{\mathrm{c}}$ Pre-exponential factor for condensation $\left(4.7 \mathrm{~s}^{-1}\right)$

$Z_{e}$ Pre-exponential factor for evaporation $\left(3.41 \times 10^{4} \mathrm{~s}^{-1}\right)$

$\epsilon$ Void fraction (0.3)

$(\rho C)_{\text {eff }}$ Effective thermal capacity per unit volume of bed $\left(\mathrm{J} \mathrm{m}^{-3} \mathrm{~K}^{-1}\right)$ 
$\rho_{\text {air }}$ Density of air $\left(1.17 \mathrm{~kg} \mathrm{~m}^{-3}\right)$

$\rho_{\mathrm{b}}$ Density of bulk biomass within compost pile $\left(120 \mathrm{~kg} \mathrm{~m}^{-3}\right)$

$\rho_{c}$ Density of pure cellulosic material $\left(120 \mathrm{~kg} \mathrm{~m}^{-3}\right)$

$\rho_{\text {compost }}$ Density of pure cellulosic material $\left(120 \mathrm{~kg} \mathrm{~m}^{-3}\right)$

$\rho_{w}$ Density of water $\left(1000 \mathrm{~kg} \mathrm{~m}^{-3}\right)$

$\sigma$ Liquid water-to-compost weight ratio $\left(\frac{W M_{w}}{W_{w}+(1-\epsilon) \rho_{\text {compost }}}\right)$

$\sigma_{\mathrm{a}}$ Activation limit of liquid water-to-compost weight ratio (0.15)

$\sigma_{b}$ Deactivation limit of liquid water-to-compost weight ratio $(0.8)$

$\sigma_{\mathrm{m}}$ Optimum limit of liquid water-to-compost weight ratio (0.6)

\section{References}

[1] F. Akgun and R. H. Essenhigh, Self-ignition characteristics of coal stockpiles: theoretical prediction from a two-dimensional unsteady-state model, FUEL, 80, 409-415, 2001, doi:10.1016/S0016-2361(00)00097-1 C36

[2] P. C. Bowes, Self-heating: Evaluating and Controlling the Hazards, Elsevier Press, Amsterdam, The Netherlands, 1984. C35, C36

[3] W. F. Brinton, E. Jr. Evans, M. L. Droffner and R. B. Brinton, Standardized test for evaluation of compost self-heating, BioCycle, 36, 60-65, 1995, http://www.jgpress.com C35

[4] X. D. Chen, On the fundamentals of diffusive self-heating in water containing combustible materials, Chemical Engineering and Processing, 37, 367-378, 1998. C39

[5] FlexPDE ${ }^{\mathrm{TM}}, P D E$ Solutions Inc, http://www.pdesolutions.com C40 
[6] B. F. Gray, M. J. Sexton, B. Halliburton and C. Macaskill, Wetting-induced ignition in cellulosic materials, Fire Safety Journal, 37, 456-479, 2002, doi:10.1016/S0379-7112(02)00002-4 C39, C40

[7] R. T. Haug, The Practical Handbook of Compost Engineering, Lewis Publishers, USA, 1993. C36, C37, C41, C42, C45, C46

[8] W. Hogland, T. Bramryd and I. Persson, Physical, biological and chemical effects of unsorted fractions of industrial solid waste fuel storage, Waste Management and Research, 14, 197-210, 1996, doi:10.1006/wmre.1996.0019 C36

[9] P. F. Hudak, Spontaneous combustion of shale spoils at sanitary landfill, Waste Management and Research, 22, 687-688, 2001, doi:10.1016/S0956-053X(01)00077-0 C35

[10] M. Khanahmadi, R. Roostaazad, A. Safekordi, R. Bozorgmehri and D. A. Mitchell, Investigating the use of cooling surfaces in solid-state fermentation tray bioreactors: modelling and experimentation, Journal of Chemical Technology and Biotechnology, 79, 1228-1242, 2004, doi: 10.1002/jctb.1117 C39

[11] M. Krajčiová, L'. Jelemenský, M. Kiša and J. Markoš, Model prediction on self-heating and prevention of stockpiled coals, Journal of Loss Prevention in the Process Industries, 17, 205-216, 2004, doi:10.1016/j.jlp.2004.02.002 C37

[12] F. Kuwahara, Y. Sano, A. Nakayama, K. Nakasaki and T. Fukazawa, Numerical modelling of a composting process with aeration, Journal of Porous Media, 10(12), 927-938, 2009. C36, C40

[13] T. Luangwilai, H. S. Sidhu, M. I. Nelson and X. D. Chen, Modelling the effects of moisture content in compost piles, Proceedings of the 39th Australian Chemical Engineering Conference, Chemeca-2011, Engineers Australia, 2011, 
http: //www. conference.net.au/chemeca2011/papers/411.pdf C36, C41, C46

[14] T. Luangwilai and H. S. Sidhu, Determining critical conditions for two-dimensional compost piles with air flow via numerical simulations, ANZIAM J.(E), 52, pp. C463-C481, 2011, http://anziamj .austms . org.au/ojs/index.php/ANZIAMJ/article/view/3753 C40

[15] N. O. Moraga, F. Corvalan, M. Escudey, A. Arias and C.E. Zambra, Unsteady 2D coupled heat and mass transfer in porous media with biological and chemical heat generations, International Journal of Heat and Mass Transfer, 52, 5841-5848, 2009, doi:10.1016/j.ijheatmasstransfer.2009.07.027 C36

[16] D. Nield and A. Bejan, Convection in porous media, Springer-Verlag, New York, 1992. C37

[17] R. Rynk, Fires at composting facilities, BioCycle Magazine, 41(1), 54-62, 2000, http://www.jgpress.com C35, C36, C37, C41, C43, C44, C46

[18] M. J. Sexton, C. Macaskill and B. F. Gray, Self-heating and drying in two-dimensional bagasse piles, Combustion Theory and Modelling, 5, 517-536, 2001, doi:10.1088/1364-7830/5/4/302 C39

[19] R. A. Sisson, A. Swift, G. C. Wake and B. F. Gray, The self-heating of damp cellulosic materials: I. High thermal conductivity and diffusivity, IMA Journal of Applied Mathematics, 49, 273-291, 1992, http://ftp.math.utah.edu/pub/tex/bib/toc/imajapplmath.html C39

[20] H. S. Sidhu, M. I. Nelson and X. D. Chen, A simple spatial model for self-heating compost piles, ANZIAM J., 48(CTAC2006), C135-C150, 2007, http://anziamj.austms.org.au/ojs/index.php/ANZIAMJ / article/view/86 C36, C38, C40, C41 


\section{Author addresses}

1. T. Luangwilai, Applied and Industrial Mathematics Research Group, School of Physical, Environmental and Mathematical Sciences, University of New South Wales at the Australian Defence Force Academy, Canberra, ACT 2600, Australia.

mailto:t.luangwilai@student.adfa.edu.au

2. H. S. Sidhu, Applied and Industrial Mathematics Research Group, School of Physical, Environmental and Mathematical Sciences, University of New South Wales at the Australian Defence Force Academy, Canberra, ACT 2600, Australia.

3. M. I. Nelson, School of Mathematics and Applied Statistics, University of Wollongong, Wollongong, NSW, AUstralia. 